\title{
Comparison of the effects of on-pump and off-pump coronary artery bypass surgery on cerebral oxygen saturation using near-infrared spectroscopy
}

\author{
Guray Demir, Zafer Çukurova, Gülay Eren, and Oya Hergünsel \\ Department of Anesthesiology and Reanimation, Bakirkoy Dr. Sadi Konuk Training and Research Hospital, Istanbul, Turkey
}

Background: Central nervous system complications are the most clinically important of those affecting mortality in patients undergoing coronary artery surgery. Newly developed sophisticated techniques and surgical interventions obviating the need for cardiopulmonary pumps have facilitated avoidance of these complications. In this study, we compared the impact of on-pump and off-pump coronary artery bypass surgery on cerebral oxygenation using near-infrared spectroscopy.

Methods: This study included 40 patients with no comorbidities who were scheduled for on-pump $(\mathrm{n}=20)$ and offpump $(\mathrm{n}=20)$ cardiac surgery. Preoperative and postoperative Standardized Mini-Mental State Examination (SMMSE) scores, perioperative mean arterial blood pressure (MAP), hematocrit ( Hct), peripheral oxygen saturation $\left(\mathrm{SpO}_{2}\right)$, regional cerebral oximetry values $\left(\mathrm{rSO}_{2}\right)$, body temperature, and partial pressure of carbon dioxide $\left(\mathrm{PCO}_{2}\right)$ were recorded, for all patients. Intergroup and intragroup comparisons were then performed.

Results: The mean operative time was longer in the on-pump group. SMMSE scores were similar and relevant postoperative values were lower in both groups. Perioperative $\mathrm{MAP}, \mathrm{PCO}_{2}$, and $\mathrm{SpO}_{2}$ were similar in both groups. $\mathrm{SpO}_{2}$ and $\mathrm{PCO}_{2}$ did not differ from baseline levels in either group, while the postextubation MAP at $2 \mathrm{~h}$ postoperatively remained low. Hct levels decreased during the perioperative and postoperative periods, while the body temperature declined perioperatively and to a greater degree in the on-pump group. The intraoperative and postoperative $\mathrm{rSO}_{2}$ decreased in both groups. In the on-pump group, the decrease in $\mathrm{rSO}_{2}$ was more prominent during the interval between the start and closure of the sternotomy.

Conclusions: Physiological alterations that occur during coronary artery surgery affect cerebral oxygenation during and after the operation irrespective of the application of a cardiopulmonary pump. Cerebral oxygenation decreases to a greater extent during on-pump surgery; however, probably because of the neuroprotective effects of hypothermia, the postoperative changes resemble those of off-pump surgery. (Korean J Anesthesiol 2014; 67: 391-397)

Key Words: Cerebral protection, Coronary artery bypass, Near-infrared spectroscopy.

Received: February 4, 2014. Revised: 1st, April 4, 2014; 2nd, April 28, 2014; 3rd, May 19, 2014; 4th, July 7, 2014. Accepted: July $15,2014$.

Corresponding author: Guray Demir, M.D., Department of Anesthesiology and Reanimation, Bakirkoy Dr. Sadi Konuk Training and Research Hospital, Zuhuratbaba Mh, 34147, Istanbul, Turkey. Tel: 00902124147171, Fax: 00902125424491, E-mail: guraydemir@hotmail.com

(c) This is an open-access article distributed under the terms of the Creative Commons Attribution Non-Commercial License (http:// creativecommons.org/licenses/by-nc/3.0/), which permits unrestricted non-commercial use, distribution, and reproduction in any medium, provided the original work is properly cited. 


\section{Introduction}

Coronary artery surgery performed using off-pump techniques on the beating heart without resorting to cardiopulmonary bypass $(\mathrm{CPB})$ is becoming more prevalent. The main objective of the off-pump technique is avoidance of unfavorable effects of both CPB and concomitantly used body cooling methods on physiological systems. The superiority of off-pump over on-pump techniques is debated especially in patients of advanced age; in patients with a decreased ejection fraction; in the settings of reoperation, cerebrovascular disease, liver disease, and bleeding diathesis; and in patients with an extremely calcific aorta or in whom the use of whole blood or blood products is contraindicated [1-3].

Neurological damage is the most common of the noncardiac complications that occur during and after coronary artery surgery [4]. Potential neurological damage ranges widely from cognitive dysfunction to permanent neurological damage, such as stroke [5]. With various monitoring techniques. It is possible to trace both the cellular integrity and electrical activity of the central nervous system. Such techniques are employed to preclude potential neurological damage [6]. A newly developed nearinfrared spectroscopy (NIRS) technique displays the hemoglobin concentration of the brain tissue, which can be an early sign of damage [7].

In this study, we aimed to investigate the effects of on-pump and off-pump coronary artery bypass graft (CABG) techniques, the superiority and favorable and unfavorable aspects of which have been debated, on cerebral oxygenation using NIRS.

\section{Materials and Methods}

\section{Study design}

Forty patients with a diagnosis of coronary artery disease and who were scheduled to undergo CABG were included in the study. The patients comprised adults $<65$ years of age who were scheduled for anastomosis between two vessels without sex discrimination. Patients with the following characteristic features were excluded from the study: patients planned to undergo cardiac surgery for a condition other than coronary artery disease; those who were scheduled for anastomosis of the vessels of the lateral wall of the heart or a vascular intervention targeted at three or more cardiac vessels; those with previously or preoperatively known or confirmed cerebrovascular disease; candidates for cranial surgery or patients who had undergone cranial surgery; patients with an anatomic cranial defect that constituted a contraindication to NIRS examination; those with occlusive carotid artery disease or grade $\geq 2$ cardiac valvular insufficiency or stenosis; those with renal or hepatic failure, chronic obstruc- tive pulmonary disease, or systemic organ failure; those who had undergone surgery lasting more than $300 \mathrm{~min}$ or who had not been extubated within $6 \mathrm{~h}$ postoperatively; and those who had undergone reoperation for any other indication.

\section{Outcome parameters}

The mean arterial blood pressure (MAP), peak heart rate, body temperature, peripheral oxygen saturation, cerebral oxygen saturation, hemoglobin level, hematocrit (Hct), and blood gas analysis results of all study participants were recorded at the following time points: preoperatively; after the sternotomy; before and after the distal anastomosis; after the proximal anastomosis; after closure of the sternotomy; at 1,2,3, and $6 \mathrm{~h}$ postoperatively; and at 1,2, and 3 days postoperatively. The Standardized Mini-Mental State Examination (SMMSE) was performed preoperatively and 1 day postoperatively. The cerebral oxygen saturation was measured using the Invos $5100 \mathrm{C}$ cerebral oximeter (Somanetics, Troy, MI, USA). The obtained data were statistically evaluated in intragroup and intergroup comparisons. The intergroup differences were analyzed in the intergroup assessments, and the impact of the surgical process of cerebral oxygenation was evaluated in the intragroup assessments.

\section{Statistical analysis}

The Number Cruncher Statistical System 2007 and PASS 2008 Statistical Software (NCSS, Kaysville, UT, USA) software packages were used for the statistical analysis. The study data were evaluated using descriptive statistics (means \pm standard deviation). Student's t-test was used for intergroup comparison of quantitative data with a normal distribution, and the pairedsamples t-test was used for intragroup comparisons. The chisquared test was used to compare qualitative data. Statistical significance was set at $\mathrm{P}<0.05$.

\section{Results}

This study included 13 (32.5\%) female and 27 (67.5\%) male patients. The mean age of the patients was $58.22 \pm 6.45$ years. No intergroup differences were found in age, height, body weight, or sex $(\mathrm{P}>0.05)$. The operative time in the on-pump group $(228.25 \pm 23.63 \mathrm{~min})$ was longer than that in the offpump group $(150.40 \pm 9.89 \mathrm{~min})(\mathrm{P}<0.01)$.

In the intergroup comparison, the Hct in the off-pump group was higher after completion of the distal and proximal anastomosis, closure of the sternotomy, at $3 \mathrm{~h}$ postoperatively, and at 2 days postoperatively $(\mathrm{P}<0.01)$ (Fig. 1). In the intragroup comparison, however, the Hct in both groups was significantly lower than the preoperative baseline Hct after the sternotomy; after 


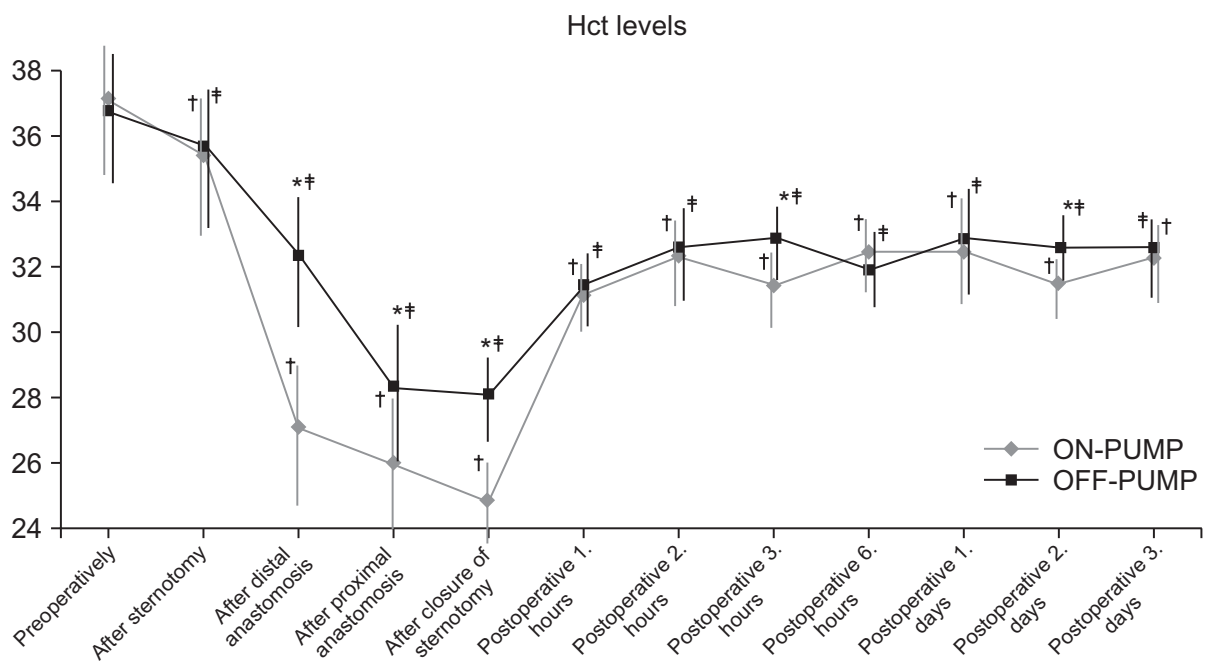

Fig. 1. Comparison of changes in hematocrit.

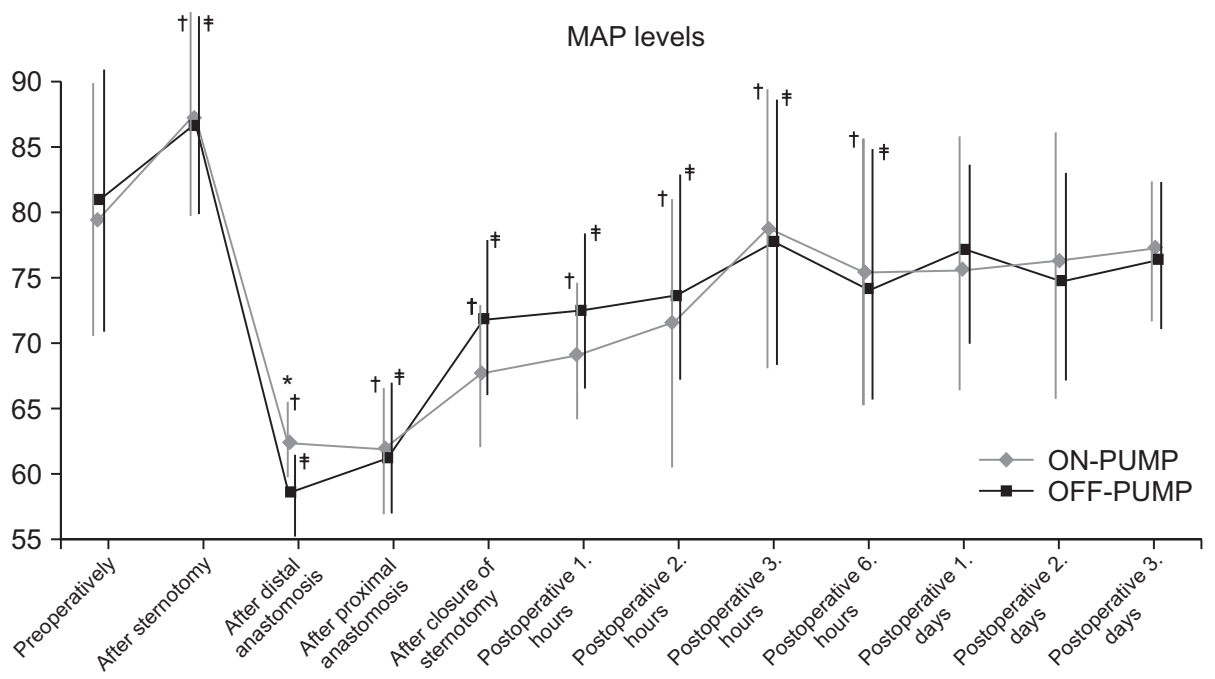

Fig. 2. Comparison of changes in mean blood pressure. closure of the sternotomy incision; after completion of the distal and proximal anastomosis; at 1, 2, 3, and 6 h postoperatively; and at 1,2 , and 3 days postoperatively $(\mathrm{P}<0.01)$ (Fig. 1 ).

In the intergroup comparison, the MAP in the on-pump group was higher than that in the off-pump group after the distal anastomosis $(\mathrm{P}<0.05)$ (Fig. 2). In the intragroup comparison, when compared with the preoperative baseline value, the MAP in the on-pump group was higher after sternotomy and lower after the distal anastomosis, after the proximal anastomosis, after closure of the sternotomy incision, and at 1 day postoperatively $(\mathrm{P}<0.01)$ as well as at $2 \mathrm{~h}$ postoperatively $(\mathrm{P}<0.05)$ (Fig. 2$)$. In the off-pump group, the MAP after sternotomy was higher than the preoperative baseline MAP $(\mathrm{P}<0.05)$, while it was lower after the distal and proximal anastomosis, after closure of the sternotomy incision, and at 1 day postoperatively $(\mathrm{P}<0.01)$ as well as at $2(\mathrm{P}<0.05), 3(\mathrm{P}<0.01)$, and 6 h postoperatively $(\mathrm{P}<0.05)$ (Fig. 2).
The $\mathrm{SpO}_{2}$ levels were comparable in the intergroup comparison $(\mathrm{P}>0.05)$. In the intragroup comparison, however, the $\mathrm{SpO}_{2}$ levels were higher than the preoperative baseline values in both groups due to the high $\mathrm{FIO}_{2}$ during the sternotomy, after the distal and proximal anastomosis, after closure of the sternotomy incision $(\mathrm{P}<0.01)$, before the distal anastomosis, at 1 day postoperatively (on-pump group, $\mathrm{P}<0.05$; off-pump group, $\mathrm{P}<0.01$ ), and at 2,3 , and $6 \mathrm{~h}$ postoperatively $(\mathrm{P}<0.01)$.

In the intergroup comparison, the body temperature was higher in the off-pump group after the distal and proximal anastomosis $(\mathrm{P}<0.01)$ (Fig. 3). However, in the intragroup comparison, the body temperature was lower than the preoperative baseline value after the sternotomy, after the distal and proximal anastomosis, and after closure of the sternotomy in both groups $(\mathrm{P}<0.01)$.

The $\mathrm{PCO}_{2}$ values did not differ in either the intragroup or intergroup comparison $(\mathrm{P}>0.05)$. 


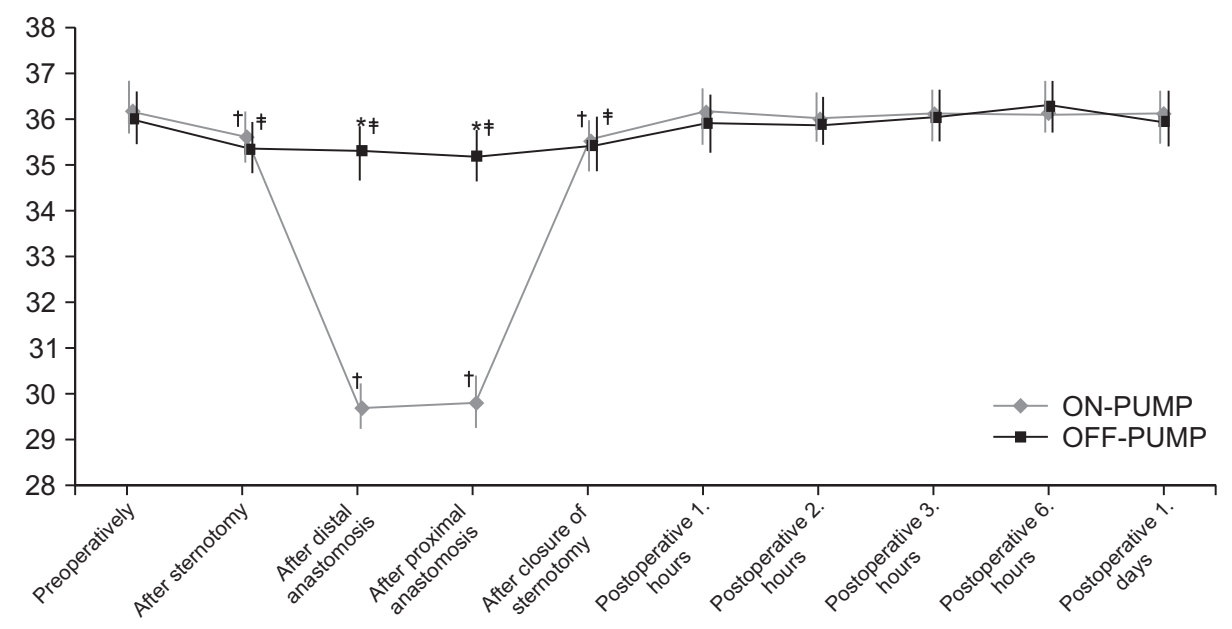

$\mathrm{rsO}_{2}$ levels

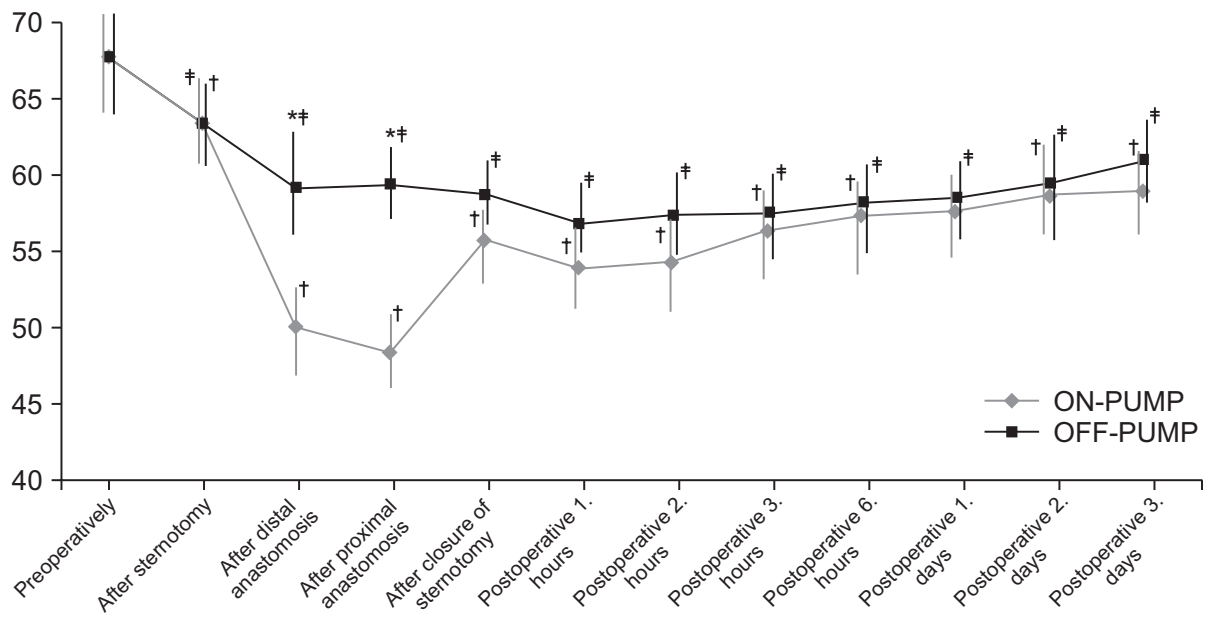

Fig. 3. Comparison of changes in body temperature.
Fig. 4. Comparison of changes in regional brain oxygenation.
In the intergroup comparisons, the mean regional cerebral oximetry value $\left(\mathrm{rSO}_{2}\right)$ was relatively higher after the proximal/ distal anastomosis in the off-pump group $(\mathrm{P}<0.01)$ (Fig. 4). In the intragroup comparison, the mean $\mathrm{rSO}_{2}$ levels were lower than the preoperative baseline values in both groups after the sternotomy (on-pump group, $\mathrm{P}<0.01$; off-pump group, $\mathrm{P}<$ 0.05); after the distal/proximal anastomosis; after closure of the sternotomy; at 1, 2, 3, and 6 h postoperatively; and at 1,2, and 3 days postoperatively $(\mathrm{P}<0.01)$.

The SMMSE scores did not differ between the two groups $(\mathrm{P}>0.05)$. However, in the intragroup comparison, the postoperative SMMSE scores were lower than the preoperative baseline SMMSE scores in both groups (on-pump group, $\mathrm{P}<0.01$; offpump group, $\mathrm{P}<0.05)$.

\section{Discussion}

Off-pump CABG operations are being performed more fre- quently because of the development of sophisticated technical equipment and surgical techniques [8-10]. Despite these innovations, the advantage of off-pump over on-pump techniques with respect to perioperative and postoperative complications remains a subject of debate. The favorable outcomes of offpump techniques in patients with serious risk factors, such as lower ejection fractions, established cerebrovascular disease, and advanced age, have been particularly acknowledged [10,12]. Some studies have demonstrated that this technique reduces the amount of blood products required and the need for intraaortic balloon pump application, and significantly improves postoperative cardiac enzyme levels with resultant decreases in the incidence of in-hospital mortality, perioperative myocardial infarction, and complications during the early postoperative period. However, other researchers have found similarities between the two CABG techniques with respect to the incidence of in-hospital mortality and major complications [12,15].

Especially in elderly patients, neurological destructive 
changes are the most common noncardiac complications that occur during and after coronary artery surgery $[4,5,16]$. The major causes of neurological damage that occurs during cardiac surgery are significant hemodynamic alterations, embolization, cerebral hyperthermia, and inflammatory and neurohumoral disorders $[4,5,16]$. Another important issue in the prevention of potential neurological damage is neuromonitoring [16]. Especially during operations associated with a higher risk, shortterm neuromonitoring can detect warning signs of potential complications, allowing for necessary measures to be taken beforehand to preclude these complications. NIRS monitoring can simultaneously trace intraoperative factors that might affect cerebral oxygenation and metabolism. In patients with low cerebral oxygenation, influential factors can be overviewed and necessary measures can be rapidly taken. This approach prevents the development of potential minor and major neurological complications. In the present study, using NIRS, $\mathrm{rSO}_{2}$ of the patients which might unfavorably affect intraoperative cerebral oxygenation and metabolism, duration of operation, anastomosis and postoperative mechanical ventilation, blood pressure, $\mathrm{Hct}$, body temperature, and $\mathrm{SpO}_{2}$ and $\mathrm{PCO}_{2}$ levels were monitored and evaluated (This list is unclear; please revise to more clearly delineate the first and second parts of the sentence). Neurocognitive functions were also monitored and assessed using the SMMSE scoring system.

Although the present study was not designed to demonstrate the effect of operative times on cerebral oxygenation and the frequency of potential neurological complications, many studies have indicated that prolonged operative times have an impact on the frequency of probable neurological complications $[17,20]$. The longevity of the surgery was also an important factor in the present study. The operative times did not exceed $250 \mathrm{~min}$, even in cases in which the on-pump technique was applied for anastomosis of two vessels. In fact, studies that have demonstrated unfavorable effects of prolonged operative times on surgical outcomes involved multivessel anastomotic procedures with much longer durations [21]. Although a definitive conclusion cannot be made, prolonged operative times do not apparently increase the frequency of potential complications when using the onpump technique in one- or two-vessel bypass surgeries. In this study, despite differences in the total operative times, significant alterations in $\mathrm{rSO}_{2}$ occurred only during $\mathrm{CPB}$ and after termination of $\mathrm{CPB}$. Additionally, the $\mathrm{rSO}_{2}$ values in both groups declined to nearly pre-CPB levels. The similar $\mathrm{rSO}_{2}$ levels in both groups after $\mathrm{CPB}$ and during and after the operation suggest that prolongation of operative times due to the application of the onpump technique in patients undergoing two-vessel anastomosis does not substantially influence surgical outcomes.

In this study, the $\mathrm{SpO}_{2}, \mathrm{pO}_{2}$, and $\mathrm{PCO}_{2}$ values, which might affect neuronal metabolism with ensuing neurological damage, did not differ between the two groups. Maintenance of appropriate intraoperative ventilation and adequate gas perfusion during $\mathrm{CPB}$, as well as monitoring and management of blood gas levels, allowed the blood gas values to be maintained within the reference ranges. Thus, development of hypoxia, hyperoxia, hypocapnia, and hypercapnia and their unfavorable outcomes could be avoided.

In the present study, the on-pump technique affected the Hct more adversely because of the occurrence of normovolemic hemodilution during CPB. Similarly, many studies have demonstrated that the on-pump CABG technique increases the requirement for blood transfusions and postoperative bleeding coming through the implanted drain [2]. In this study, no decreases in the Hct that might have adversely affected cerebral oxygenation were observed during the preoperative or postoperative periods. Although the Hct showed a significantly greater decrease in the on-pump group than in the off-pump group, especially during $\mathrm{CPB}$, the Hct remained at $>21 \%$ (mean, $24.85 \% \pm 2.28 \%$ ) (Fig. 1). Previous studies have indicated that in patients with no comorbidities, an Hct of $21 \%$ during CPB does not affect cerebral oxygenation or contribute to the development of neuronal damage [22,23].

During off-pump CABG procedures, the heart rate and blood pressure are iatrogenically lowered to facilitate application of distal anastomoses. Under meticulous and controlled premedication, induction of short-term controlled hypotension does not result in serious hemodynamic changes or adverse outcomes [24]. In the present study, the iatrogenically induced decrease in the mean blood pressure during application of the distal anastomoses was substantially greater in the off-pump group than in the on-pump group; however, it did not reach a statistically significant level and remained at $58.50 \pm 4.94 \mathrm{mmHg}$ without the development of any resultant complications (Fig. 2).

Induced hypothermia is the mainstay of on-pump CABG, and lowers the cerebral metabolism to prevent neuronal damage [25]. Many studies have indicated that in on-pump CABG, moderate hypothermia and gradual warming of circulatory blood at the termination of CPB with avoidance of hyperthermia provides adequate protection against myocardium and neuronal damage [25-27]. In the present study, moderate hypothermia was applied in patients who underwent on-pump surgery. During termination of $\mathrm{CPB}$, the circulatory blood was gradually warmed and the patients were protected from the deleterious effects of hyperthermia. The body temperatures of patients in the off-pump group who were not exposed to hypothermia did not change significantly, while the mean nasopharyngeal temperature decreased to $29.65 \pm 0.63^{\circ} \mathrm{C}$ in the on-pump group during $\mathrm{CPB}$. During the postoperative period, the patients' body temperatures were maintained at 36 to $37^{\circ} \mathrm{C}$ to protect them from the adverse effects of hyperthermia (Fig. 3). 
In both groups, the regional oxygenation of the brain exhibited significant changes at different time points in parallel with changes in the factors affecting cerebral oxygenation. A significant increase in the postintubation $\mathrm{rSO}_{2}$ was observed in both groups when compared with the preoperative baseline levels. This increase was related to the sympathetic response to probable increases in blood pressure and cerebral blood flow. In both the on-pump and off-pump groups, a significant decrease occurred in the $\mathrm{rSO}_{2}$ relative to baseline values with prolongation of the operative time. This decrease continued until day 3 postoperatively and was interpreted to be an etiological factor in the decline in cognitive functioning observed in both groups. The $\mathrm{rSO}_{2}$ values significantly decreased due to CPB (Fig. 4). Because the changes in $\mathrm{MAP}, \mathrm{SpO}_{2}$, and $\mathrm{PCO}_{2}$, all of which can affect cerebral oxygenation during $\mathrm{CPB}$, were of similar magnitude in both groups, the only factor that might have caused this intergroup difference was dilutional anemia induced during $\mathrm{CPB}$. Apart from similarities in other influential factors during $\mathrm{CPB}$, the reduced Hct during $\mathrm{CPB}$ caused by induced hemodilution results in a decrease in the amount of oxygen delivered to cerebral tissue [28]. As a result, the $\mathrm{rSO}_{2}$ levels dropped more sharply during $\mathrm{CPB}$ surgery in the on-pump group. However, the similar results obtained in both the $\mathrm{rSO}_{2}$ and cognitive functions before CPB and during the immediate postoperative period indicate that this intergroup difference had no effect on the outcomes. Despite the significantly greater decrease in $\mathrm{rSO}_{2}$ during $\mathrm{CPB}$, the similar results indicate the existence of an influential neuroprotective mechanism operating during CPB. We conclude that this neuroprotective effect involves hypothermia applied during CPB surgery. Further data should be obtained in larger-scale studies involving greater numbers of patients to arrive at more robust conclusions on this issue.

In conclusion, $\mathrm{CABG}$ performed using either the on-pump or off-pump technique adversely affects cerebral oxygenation and cognitive functions both during the operation and in the immediate postoperative period. The development of innovative techniques and the experience gained in this field have decreased the potential complications to a great extent. The comparative advantages and disadvantages of on-pump and off-pump techniques are debated in the medical literature, and no consensus has been reached. This study demonstrated that despite intraoperative differences, coronary artery surgery performed using either an on-pump or off-pump technique exerts similar effects on cerebral oxygenation during the postoperative period and has a comparable impact on short-term neurocognitive function.

\section{References}

1. Mangano CM, Hill L, Cartwright CR, Hindman BJ. Cardiopulmonary bypass and the anesthesiologist. In: Cardiac Anesthesia. Edited by Kaplan JA, Reich DL, Savino JS: Philadelphia, WB Saunders Company. 1999, pp 1061-110.

2. Lancey RA, Soller BR, Vander Salm TJ. Off-pump versus on-pump coronary artery bypass surgery: a case-matched comparison of clinical outcomes and costs. Heart Surg Forum 2000; 3: 277-81.

3. Yokoyama T, Baumgartner FJ, Gheissari A, Capouya ER, Panagiotides GP, Declusin RJ. Off-pump versus on-pump coronary bypass in highrisk subgroups. Ann Thorac Surg 2000; 70: 1546-50.

4. Murkin JM. Etiology and incidence of brain dysfunction after cardiac surgery. J Cardiothorac Vasc Anesth 1999; 13 (4 Suppl 1): $12-7$.

5. Ricksten SE. Cerebral dysfunction after cardiac surgery - are we moving forward? Curr Opin Anaesthesiol 2000; 13: 15-9.

6. Sebel PS. Central nervous system monitoring during open heart surgery. J Cardiothorac Vasc Anesth 1998; 12(2 Suppl 1): 3-8.

7. Harris DN, Bailey SM. Near infrared spectroscopy in adults. Does the Invos 3100 really measure intracerebral oxygenation? Anaesthesia 1993; 48: 694-6.

8. Spooner TH, Hart JC, Pym J. A two year, three institution experience with the Medtronic Octopus: systematic off-pump surgery. Ann Thorac Surg 1999; 68: 1478-81.

9. Acuff TE, Landreneau RJ, Griffith BP, Mack MJ. Minimally invasive coronary artery bypass grafting. Ann Thorac Surg 1996; 61: 135-7.

10. Ascione R, Caputo M, Angelini GD. Off-pump coronary artery bypass grafting: not a flash pan. Ann Thorac Surg 2003; 75: 306-13.

11. Salamon T, Michler RE, Knott KM, Brown DA. Off-pump coronary artery bypass grafting does not decrease the incidence of atrial fibrillation. Ann Thorac Surg 2003; 75: 505-7.

12. Jansen EW, Borst C, Lahpor JR, Grundeman PF, Eefting FD, Nierich A, et al. Coronary artery bypass grafting without the cardiopulmonary bypass using the octopus method: results in the first one hundred patients. J Thorac Cardiovasc Surg 1998; 116: 60-7.

13. Gründeman PF, Borst C, Verlaan CW, Meijburg H, Mouës CM, Jansen EW. Exposure of circumflex branches in the tilted, beating porcine heart: echocardiographic evidence of right ventricular deformation and the effect of right or left heart bypass. J Thorac Cardiovasc Surg 1999; 118: 316-23.

14. Diegeler A, Martin M, Falk V, Binner C, Walther T, Autschbach R, et al. Indication and patient selection in minimally invasive and 'off-pump' coronary artery bypass grafting. Eur J Cardiothorac Surg 1999; 16 Suppl 1: S79-82.

15. Chamberlain MH, Ascione R, Reeves BC, Angelini GD. Evaluation of the effectiveness of off-pump coronary artery bypass grafting in highrisk patients; an observational study. Ann Thorac Surg 2002; 73: 1866-73. 
16. Arrowsmith JE, Grocott HP, Reves JG, Newman MF. Central nervous system complications of cardiac surgery. Br J Anaesth 2000; 84: 37893.

17. Engelman DT, Cohn LH, Rizzo RJ. Incidence and predictors of TIA's and strokes following coronary artery bypass grafting: report and collective review. Heart Surg Forum 1999; 2: 242-5.

18. Puskas JD, Winston AD, Wright CE, Gott JP, Brown WM 3rd, Craver JM, et al. Stroke after coronary artery operation: incidence, correlates, outcome, and cost. Ann Thorac Surg 2000; 69: 1053-6.

19. Djaiani GN. Aortic arch atheroma: stroke reduction in cardiac surgical patients. Semin Cardiothorac Vasc Anesth 2006; 10 : 143-57.

20. Girdauskas E, Kinduris S. Ischemic stroke and its risk factors after cardiac surgery. Medicina (Kaunas) 2002; 38: 250-60.

21. Meharwal ZS, Mishra YK, Kohli V, Bapna R, Singh S, Trehan N. Off-pump multivessel coronary artery surgery in high-risk patients. Ann Thorac Surg 2002; 74: S1353-7.

22. Breuer AC, Furlan AJ, Hanson MR, Lederman RJ, Loop FD, Cosgrove DM, et al. Central nervous system complications of coronary artery bypass graft surgery: prospective analysis of 421 patients. Stroke 1983; 14: 682-7.

23. González-Scarano F, Hurtig HI. Neurologic complications of coronary artery bypass grafting: case-control study. Neurology 1981; 31: 1032-5.

24. Chauhan S, Saxena N, Rao BH, Singh RS, Bhan A. A comparison of esmolol \& diltiazem for heart rate control during coronary revascularization on beating heart. Indian J Med Res 1999; 110: 174-7.

25. Tuman KJ, McCarthy RJ, Najafi H, Ivankovich AD. Differential effects of advanced age on neurologic and cardiac risks of coronary artery operations. J Thorac Cardiovasc Surg 1992; 104: 1510-7.

26. Stamou SC, Hill PC, Dangas G, Pfister AJ, Boyce SW, Dullum MK, et al. Stroke after coronary artery bypass: incidence, predictors, and clinical outcome. Stroke 2001; 32: 1508-13.

27. Taylor KM. Cardiac surgery and the brain. London, Edward Arnold. 1993, pp 1-14.

28. Ascione R, Williams S, Lloyd CT, Sundaramoorthi T, Pitsis AA, Angelini GD. Reduced postoperative blood loss and transfusion requirements after beating heart coronary operations: a prospective randomised study. J Thorac Cardiovasc Surg 2001; 121: 689-96. 